\title{
Autoevaluación de las prácticas académicas del Programa de bacteriología y laboratorio clínico de la Universidad Colegio Mayor de Cundinamarca
}

\author{
Elizabeth Rodríguez Hernández MSc. ${ }^{1}$ y Lucía Constanza Corrales Ramírez MSc ${ }^{1}$ \\ 1 Docente Universidad Colegio Mayor de Cundinamarca, programa de Bacteriología y Laboratorio Clínico. \\ Recibido:02-08-2004;Aceptado: 10-10-2004
}

\begin{abstract}
Resumen
El propósito de esta investigación fue evaluar el estado actual de las prácticas académicas del Programa de Bacteriología y Laboratorio Clínico de la Universidad Colegio Mayor de Cundinamarca (UCMC), según los criterios establecidos por el Concejo Nacional de Acreditación (CNA), para programas en el área de la salud, que se constituyen como uno de los desafíos para la formación de profesionales integrales, a través de los escenarios de rotación, definidos como los lugares donde los estudiantes de cualquier disciplina del área de la salud pueden realizar actividades de aprendizaje y a la vez prestar un servicio. Estos lugares pueden ser hospitales, clínicas, laboratorios farmacéuticos, centros de investigación en animales, empresas aseguradoras en salud e industria que deben cumplir con los requisitos establecidos para pactar convenios docente asistenciales. En el ámbito educativo las instituciones deben garantizar la calidad y eficiencia de los profesionales que allí se forman; de ahí que resulte necesario hablar de evaluación tanto de programas, currículos, estudiantes e instituciones formadoras como escenarios de práctica.
\end{abstract}

Palabras claves: rotación, convenios, calidad, eficiencia, evaluación de programas, acreditación de programas.

\begin{abstract}
Bacteriology and clinical laboratory program autoevaluation of academic rotation of Colegio Mayor de Cundinamarca University.

The purpose of this research was to evaluate the actual condition of Academics rotation in Bacteriology and Clinical Laboratory Program in Colegio Mayor de Cundinamarca University (CMCU) according to the criteria established by Accreditation National Council (ANC) to health programs which are constituted as one of the challenges to form integral professionals, through rotation settings defined as settings where all kind of students in health area can develop learning activities and also to offer service. These places can be hospitals, clinics, pharmaceutical laboratories, animal research centres, health insurance companies and industries which must carry out with all requirements established to make agreements with them. In educational scope, institutions
\end{abstract}

Correspondencia: erodriguezh@unicolmayor.edu.co 
must guarantee quality and efficiency of all professionals that work there. In this way is necessary to talk about evaluation not only in academic programs, learning Institutions and students but also in Practice Settings.

Key words: rotation, agreements, quality, efficiency, program evaluation, guarantee in programs.

\section{Introducción}

Es innegable que las instituciones de educación superior, dada sus condiciones y características actuales se ven comprometidas a enfrentar una serie de desafíos producto de la globalización e internacionalización del conocimiento, así como por la agudización de la crisis de los estados nacionales de América Latina, donde Colombia no es la excepción (1).

La universidad no puede ser ajena a estas situaciones y debe en el corto plazo modernizar su misión académica y social para potencializar su relación con la sociedad; redefiniendo el proyecto social universitario lo cual implica pensar en la necesidad de formular una política de proyección social, que articule la investigación, la docencia y la extensión a través de las prácticas académicas, como una estrategia para la modernización de la educación superior en Colombia (2).

Para responder a las necesidades de calidad en la educación superior, se creó el Sistema Nacional de Acreditación con el objetivo fundamental de garantizar a la sociedad que las instituciones de educación superior que hacen parte del sistema, cumplan con los más altos requisitos de calidad y que por lo tanto logren sus propósitos y objetivos (3). Así, la Ley previó la creación del Consejo Nacional de Acreditación (CNA), integrado por representantes de las comunidades académicas y científicas, como un ente encargado de organizar y presidir todo el proceso de acreditación, ya que el ejercicio de la función universitaria es ser parte del proceso de transformación social y de la búsqueda del desarrollo integral de estudiantes, profesores y de la sociedad de la cual hacen parte.

Los procesos de modernización curricular hacen parte del proyecto de la universidad moderna; en este sentido, es una opción cultural, una necesidad significante en el proceso de construcción de modalidades educativas, alternativas y congruentes con la socialización en las competencias, aptitudes y valores que demanda una nueva formación académica o profesional.

Así mismo, la necesidad de reconocer diferentes dimensiones de la formación académica y profesional implica conformar nuevas formas de trabajo interdisciplinario, al abordar las relaciones entre la ciencia, la tecnología, la sociedad y la cultura (3).

Frente a este panorama, al interior del programa surgió el cuestionamiento, ¿la calidad de las prácticas académicas que actualmente desarrolla el programa de Bacteriología y Laboratorio Clínico de la UCMC, responden a una interrelación vital entre la docencia, la investigación y la proyección social; para formar profesionales capaces de responder al proceso de transformación social? Para abordar este interrogante, fue necesario verificar si el proceso enseñanza-aprendizaje formula objetivos en función de lo que se espera que aprenda el estudiante y si la práctica académica, funciona como estrategia pedagógica que articula la teoría con la práctica y potencializa la capacidad adaptativa del profesional.

Por esto, se hace necesario aplicar un modelo que permita la autoevaluación y la autorregulación de la condición de las prácticas académicas frente a los estándares básicos de calidad para los centros de formación práctica en salud, como mecanismo para cuantificar y comparar la calidad de los procesos que se desarrollan y de los productos que se ofrecen (4).

\section{Materiales y métodos:}

Categorías de análisis: para el abordaje del estudio se tuvieron en cuenta dos categorías de análisis: (i) procesos académicos (plan de estudios) (ii) relación docencia-servicio. Las categorías de análisis para este 
estudio corresponden a las condiciones mínimas de calidad para los centros de formación en salud, propuestos en el Plan multidisciplinario para la modernización de formación en salud, por el Ministerio de Salud y El Consejo Nacional de Acreditación (3).

Prueba piloto: mediante la cual se evidenciaron criterios de claridad, pertinencia, eficiencia y eficacia de los instrumentos, con el fin de aplicarlos en la muestra seleccionada, considerando los requisitos mínimos de calidad propuestos. La información obtenida fue triangulada con el análisis de contenido que se efectuó contrastando los documentos referentes a las prácticas académicas del programa (convenio docente asistencial, reglamento de práctica, programa analítico de la asignatura de práctica), en concordancia con la legislación actual (Ley 100 de 1993, Decreto 0190 de 1996) (5-6).

Diseño metodológico: la investigación adoptó un diseño metodológico no experimental, correlacional, de tipo evaluativo (7), con enfoque práctico y un diseño muestral probabilístico de tipo aleatorio estratificado.
Población y muestra: la población se dividió en varios estratos así: estudiantes, profesionales de los laboratorios de las instituciones quienes desarrollan actividades de docencia- servicio, docentes de la práctica académica de la universidad, egresados del actual plan de estudios del programa de Bacteriología y Laboratorio Clínico y empleadores de los egresados del programa.

El tamaño de la muestra se determinó mediante análisis de potencia. En el estudio participaron: 79 estudiantes; instrumento de encuesta No 1, 53 profesionales de los escenarios de práctica; instrumento No 2 (43 por encuesta y 10 por entrevista), 6 docentes de práctica del programa; instrumentos No 1 y 2 (todos por entrevista), 65 egresados; instrumento No1, (55 por encuesta y 10 por entrevista), 34 empleadores; instrumento No 2 ( 28 por encuesta y 6 por entrevista).

\section{Resultados}

Categoría de análisis: (i) procesos académicos plan de estudios (3). En la figura 1, se presenta un consolidado de los seis indicadores evaluados en los

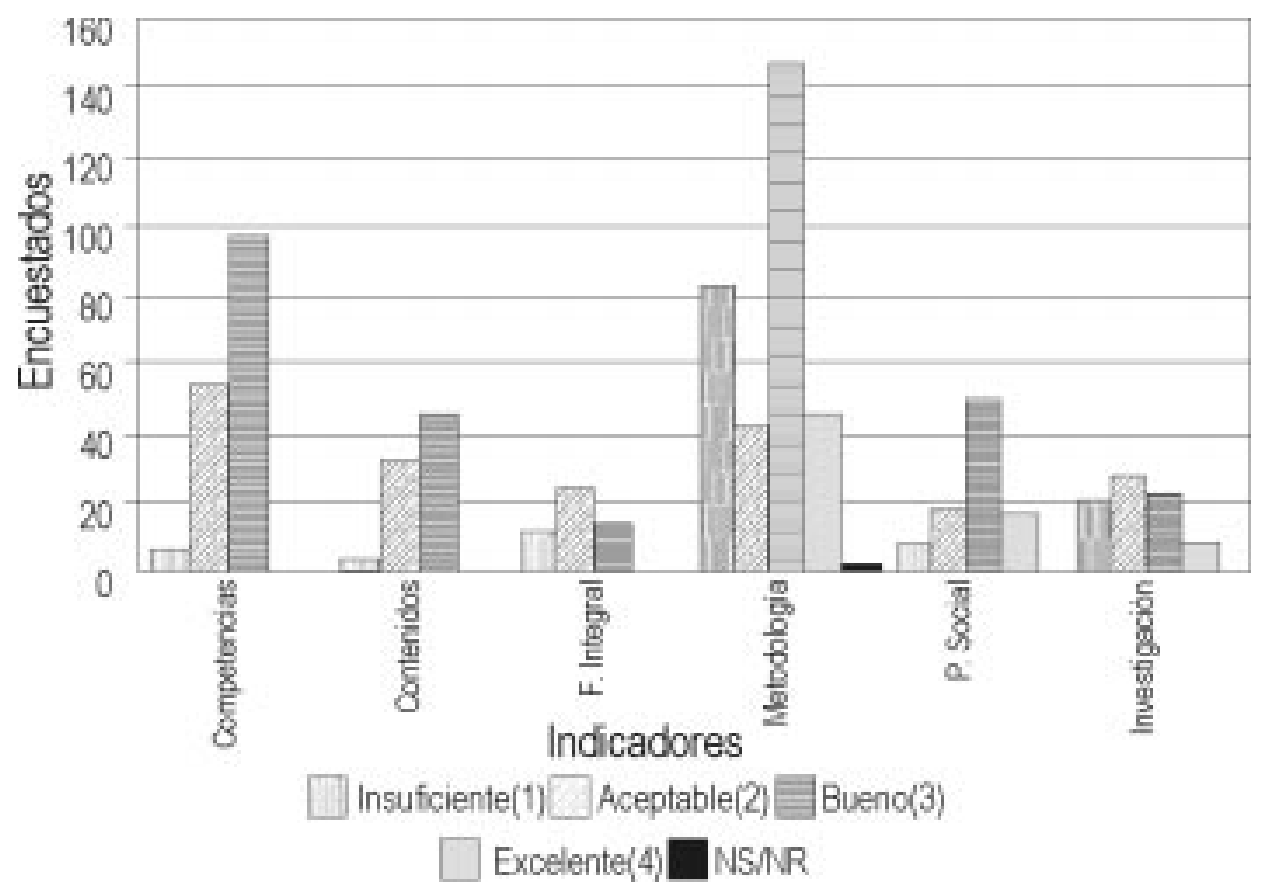

Figura 1. Resultados del instrumento 1, obtenidos en cada uno de los indicadores de la categoría de análisis Plan de Estudios. 
diferentes estratos incluidos en la muestra, de la categoría de análisis: (i) procesos académicos - plan de estudios

Indicadores: (i) competencias: los egresados entrevistados y encuestados en su mayoría opinaron que las competencias sobre las que se indagaron se encuentran en alto grado de desarrollo, destacando las de tipo valorativas y psicomotoras, las cuales, permiten al profesional una formación autónoma, ética, responsable y el desarrollo de habilidades y destrezas para el desempeño en los diferentes campos de acción.

De igual forma manifestaron; "esta formación se adquiere durante la carrera, gracias al compromiso de la universidad con la formación de profesionales integrales y comprometidos con el servicio a la comunidad y al país".

Otro sector de la población, considera; "la formación profesional se fundamenta en el conocimiento, pasando a un segundo plano el desarrollo de las competencias personales".

En general, el grupo de encuestados otorgaron al desarrollo de las competencias de tipo universal un nivel alto de calificación. Sin embargo, ocupan el último lugar entre las demás, ya que consideran que la ejecución de las actividades complementarias a los conocimientos teóricos tradicionales, como son el manejo de la tecnología y la participación en actividades culturales no se desarrollan con suficiencia debido al poco tiempo con el que cuentan los estudiantes durante su rotación y a los espacios limitados que no permiten su participación en este tipo de actividades.

De otro lado, se puede observar que tanto las apreciaciones que tienen los estudiantes como la de los egresados coinciden en calificar en alto grado de desarrollo las competencias de tipo valorativo, psicomotor, personal, emocional y mental; lo que permite deducir que existe una correlación adecuada entre el conocimiento adquirido y su aplicación en los diferentes niveles de práctica, acorde con el perfil profesional proyectado por la UCMC.

Así mismo, los estudiantes presentan opiniones divididas frente a la calificación del desarrollo de competencias, evaluado entre aceptable y alto; mientras que los egresados lo apreciaron en grado medio; especialmente en lo que se refiere a las competencias correspondientes a la creatividad, la crítica y a las de tipo universal; afirmando que esta situación puede deberse a que la universidad no brinda espacios suficientes para el desarrollo de actividades complementarias durante el proceso de la práctica académica.

Los docentes de práctica consideraron que las competencias desarrolladas en más alto grado son las psicomotoras, conceptuales, comunicativas, creativas y personales. Esta apreciación fue justificada por ellos conceptuando que el desarrollo las competencias en general se ve retroalimentado permanentemente, en lo que se refiere a las de tipo conceptual mediante la correlación permanente de los conceptos teóricos con el quehacer profesional en el laboratorio; las comunicativas, mediante la interacción de los estudiantes con profesionales de grupos interdisciplinarios, con los usuarios de los servicios, colegas de trabajo y personal de apoyo en la institución de práctica; de otra parte la creatividad cobra fuerza a través de las actividades complementarias a la práctica como son: presentación de seminarios, club de revistas, apoyo en actividades administrativas, charlas de tipo educativo, elaboración de manuales de procedimientos entre otros y las de tipo personal mediante un ejercicio responsable y comprometido en sus acciones del diario vivir de la práctica, afianzando la madurez profesional. De la misma forma, manifestaron que las competencias de tipo universal en lo que se refiere a las actividades culturales no han logrado un pleno desarrollo debido a que no existen suficientes espacios en las entidades de práctica ni en la universidad, para la participación de los estudiantes en actividades de este tipo.

www.unicolmayor.edu.co 
Indicadores: (ii) contenidos: la población encuestada y entrevistada en general encontró correspondencia entre los contenidos del plan de estudios y los objetivos propuestos en las prácticas académicas, lo cual ha permitido fortalecer la formación del profesional.

Se encontraron deficiencias en la ubicación de algunas asignaturas como es el caso de virología, inmunología y correlación clínica, las cuales los egresados consideraron que es necesario cursarlas antes de comenzar las prácticas, para lograr mayor eficiencia en el desarrollo de las mismas.

De igual forma, algunos entrevistados informaron que en las unidades temáticas contempladas en el estudio de la parasitología, no se asignan los suficientes espacios para la práctica del diagnóstico de las patologías tropicales, concernientes a la realidad epidemiológica del país.

Por otro lado, algunos egresados manifestaron haber encontrado dificultad en la ubicación de algunos procesos de laboratorio de bioquímica, por cuanto los conocimientos específicos contemplados en esta asignatura corresponden más a los procesos de química clínica.

Aunque los estudiantes encontraron los horarios y la intensidad de la práctica adecuados, los egresados y los docentes manifestaron que están de acuerdo con ellos pero solo en lo referente al primer nivel de práctica, en los otros dos niveles difieren, pues consideran que el tiempo no es suficiente para responder eficientemente con todos los procesos.

Indicadores: (iii) formación integral: frente a este indicador se analizaron dos aspectos: el primero, está relacionado con el desarrollo de valores personales y el afianzamiento del carácter y la ética. Estos dos aspectos fueron considerados por todos los sectores con un excelente grado de desarrollo; este resultado esta en relación directa con la misión de la universidad y el reglamento de la práctica académica; que enfatizan en la formación de valores.
El segundo aspecto, está relacionado con la deficiencia en la asignación de espacios para la participación de los estudiantes que cursan la práctica académica, en actividades de índole cultural en los escenarios de práctica; observándose dos situaciones concretas: en el primer nivel de práctica se limita el tiempo del estudiante a la realización de procesos rutinarios del laboratorio clínico y no se ofrecen espacios suficientes para la participación en actividades que favorezcan en el la interdisciplinariedad, el análisis y la correlación entre otros, como aspectos relevantes de su formación integral primando la asistencia sobre la docencia.

Por el contrario, en las prácticas de segundo y tercer nivel esta situación no es tan crítica, se observo un mayor protagonismo del estudiante en la participación en diferentes actividades derivadas y anexas a la práctica, debido a que la naturaleza de las mismas en estos niveles conceden mayor tiempo para el análisis, la interpretación y correlación de resultados, debido al volumen moderado de muestras procesadas, así como a la madurez y competencia profesional demostrada por los estudiantes de noveno y décimo semestre.

Indicadores: (iv) metodología: según el estudio, en los diferentes niveles de práctica los estudiantes tienen acceso a la correlación teórico práctica y a la integración con la tecnología de punta, pues se comienza por un nivel básico y fundamental; luego se ofrece la panorámica de los diferentes campos de rotación especializados y por último existe la posibilidad de profundizar en el área de su preferencia mediante la práctica electiva.

Se observó, que la docencia recibida está condicionada por factores intrínsecos al estudiante como son la motivación, el interés, la madurez y las expectativas que tenga sobre la realización de su proyecto de vida. En general se consideró, que el hecho de que existan tres niveles de práctica es una gran fortaleza que abre posibilidades y despierta expectativas en el 
estudiante, es necesario reiterar la acotación que hicieron los egresados acerca de la importancia de haber cursado todas las asignaturas antes de salir a la práctica académica.

En cuanto a la variable referente al desarrollo de procesos académicos y la intensidad horaria asignada, se encontró una interesante apreciación por parte de los egresados, los cuales manifestaron que la primera rotación tiene el tiempo adecuado pero es rutinaria, se repiten procesos aprendidos y se pierde el objetivo de la docencia-servicio, pues al estudiante se capacita en las diferentes técnicas de laboratorio y se espera que durante el resto de la rotación responda con la realización de los mismos y no se dedica el tiempo necesario a las actividades propias del aprendizaje; como la revisión de artículos científicos, correlación clínico patológica y realización de microproyectos de investigación.

Los docentes de práctica, se refirieron al hecho de que en el segundo nivel los estudiantes de noveno semestre deberían tener una sola rotación durante el periodo académico, pues cuando el estudiante está familiarizado con el trabajo y aporta a los procesos debe continuar con la siguiente práctica, situación que demanda en estos sitios un nuevo esfuerzo en el entrenamiento y el beneficio recibido para la institución es mínimo; concluyendo, que los estudiantes de segundo y tercer nivel de práctica deberían contar con un mayor tiempo disponible para permanecer en los sitios de práctica, con el fin de integrarse mejor al trabajo y contar con espacios de participación en actividades de tipo asistencial, académico y cultural.

En lo que se refiere al seguimiento y monitoreo de la práctica académica, todos los sectores consultados observaron una acertada planeación y ejecución e hicieron algunas sugerencias para su fortalecimiento, tales como: aumentar el tiempo de diálogo con el estudiante en las visitas de supervisión y que este no se limite sólo a la entrevista con el profesional o coordinador del laboratorio.
Respecto a esta situación los docentes coordinadores de práctica señalaron que requieren de mayor tiempo para realizar con eficiencia esta labor académica, dado el número de estudiantes y de escenarios de práctica asignados conlleva a que la frecuencia de las visitas se disminuya, dificultando detectar problemas a tiempo y generar acciones de mejoramiento oportuno. Así mismo, solicitan que la universidad considere dentro de su presupuesto un rubro para los gastos de desplazamiento que genera la actividad de la práctica académica.

La variable que se refiere al sistema de evaluación de los objetivos propuestos para la práctica, generó diferentes opiniones en la población involucrada en el estudio. El sector de egresados afirmó, que no existe claridad en el sistema de evaluación por cuanto en muchos sitios de rotación los profesionales encargados de la docencia servicio se limitan a observar en este proceso el desarrollo de habilidades y destrezas dejando de lado otros componentes importantes del aprendizaje, especialmente en la rotación de laboratorio clínico.

Así mismo, manifiestan que los docentes de práctica no realizan una evaluación con un instrumento determinado, específico para la temática manejada en cada rotación y aunque se desarrollan trabajos, informes y evaluaciones apreciativas de tipo oral, en la mayoría de los casos esta se enfoca únicamente al cumplimiento de los objetivos propuestos de acuerdo con los criterios establecidos en el formato de evaluación institucional.

Con respecto a la situación de la evaluación en la práctica de segundo y tercer nivel, se observó que hay un cambio en la metodología de la evaluación, porque esta ligada al producto o resultado del trabajo que debe presentar el estudiante, el cual es diverso y en la mayoría de los casos centrado en investigación, producción de artículos, estandarización de técnicas, elaboración de manuales de procedimientos y en algunos casos funciones de índole administrativo entre 
otras, actividades que además conducían a fortalecer el trabajo interdisciplinario.

En general las deficiencias encontradas en el proceso de la evaluación fueron atribuidas a que los profesionales que cumplían con las funciones de docencia asistencia, en la mayoría de los casos no contaban con formación pedagógica y desconocían el sistema de evaluación por competencias.

Indicadores: (v) proyección social: este indicador se encuentra permeado por un sesgo en opinión de los egresados y estudiantes, debido a que no existe claridad en la definición del término "proyección social", ya que la mayoría piensan que el contacto con los pacientes en el nivel de laboratorio clínico se considera como una acción de proyección a la comunidad.

En este mismo sentido se aprecio claridad en la comprensión del término por parte de los docentes de práctica quienes afirmaron que es necesario servirse de la práctica académica como estrategia para fortalecer la proyección social y la investigación, afirmando que es una posibilidad tangible de ayudar a solucionar los problemas que presentan las comunidades del entorno sobre las cuales se tiene influencia.

Otro aspecto analizado, fue el referente a si la práctica académica facilitaba el fortalecimiento y/o desarrollo de la formación investigativa en proyectos generados de las problemáticas en salud del entorno, la mayoría de la población de estudio, manifestó que su participación en procesos de formación investigativa, se limitó a proyectos de investigación derivados de los intereses propios de las instituciones de práctica, sin tener relación directa con los problemas de salud del entono o en la mayoría de casos no se desarrollan proyectos de investigación.

Una de las razones generalizadas que dan respuesta a esta problemática es que el volumen de trabajo asignado a los profesionales encargados de la docencia-servicio y a los estudiantes en rotación no facilita los espacios suficientes para generar proyectos de investigación. Una fortaleza que se identificó es el desarrollo de las asignaturas de diseño y desarrollo de proyectos que cursan los estudiantes en el programa, estas generan un buen número de proyectos de investigación que pueden ejecutarse en conjunto con las instituciones de práctica.

Indicadores: (vi) investigación: aunque la investigación es uno de los pilares fundamentales que soporta el quehacer de la universidad, en general se observó que en los objetivos de las prácticas académicas únicamente se contemplaba la participación de los estudiantes en términos de colaborador y observador en los proyectos de investigación de las instituciones de práctica y no se percibía como objetivo la generación de proyectos de investigación.

En el primer nivel de práctica, no se han generado hasta ahora espacios formales para la realización de microproyectos en las diferentes áreas del laboratorio clínico, como resultado de un objetivo específico. En la rotación de segundo nivel, se cuenta con mayores posibilidades de participación en proyectos de investigación por que el mismo carácter de la rotación lo permite, esto sumado a que en este semestre el estudiante debe desarrollar el proyecto de investigación requerido para optar su titulo profesional.

En el tercer nivel, se aprecia una mayor participación de los estudiantes en actividades de índole investigativo por el hecho de ser una práctica electiva, el estudiante tiene la posibilidad de seleccionar instituciones que se dedican a la investigación y así fortalecer su perfil profesional como investigador.

Por otra parte, la universidad ofrece flexibilidad para que los estudiantes que realizan investigación, roten por las entidades de práctica en las cuales adelantan sus proyectos. Los egresados manifestaron inconformidad respecto a los criterios de selección de estudiantes para adelantar prácticas en instituciones de investigación, pues estas rotaciones son asignadas a estudiantes con buen rendimiento académico, con exclusión de otros con interés por la investigación. Así mismo, la participación de los docentes 


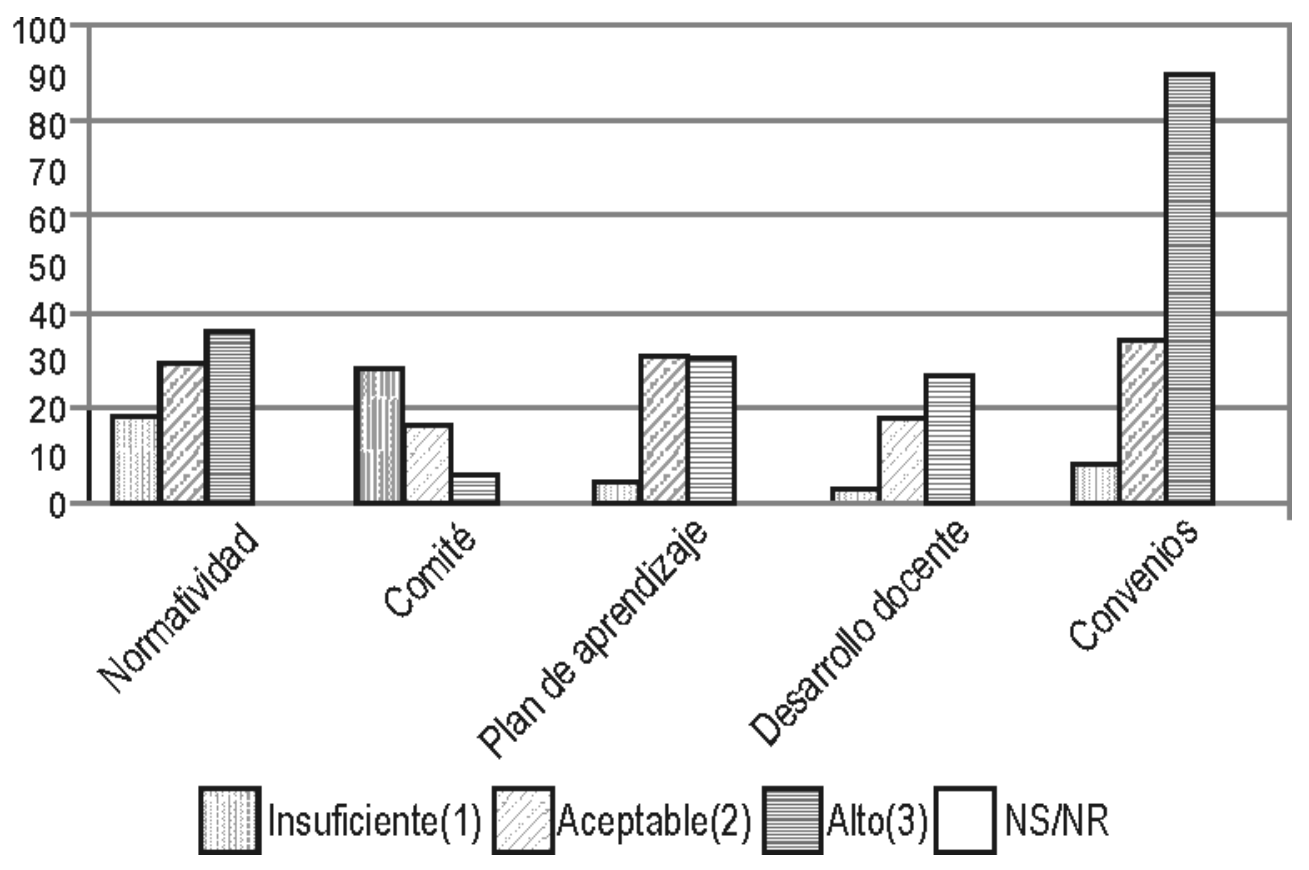

Figura 2. Resultados obtenidos del instrumento 2 en cada uno de los indicadores de la categoría (ii) procesos relación docencia-servicio

de práctica en proyectos de investigación generados desde esta actividad es casi nula.

Categoría de análisis: (ii) relación docencia-servicio (3). En la figura 2, se presenta el consolidado de los seis indicadores evaluados en los diferentes estratos de la muestra, de la categoría de análisis: (ii) procesos relación docencia-servicio

Indicadores: (i) normatividad: con respecto a si la actividad de docencia servicio se realiza con conocimiento previo del reglamento de práctica y del convenio de docencia asistencia, se observa en general que la actividad de docencia asistencia se realiza bajo las normas que reglamentan el tema, pero existe bastante desconocimiento por parte de los profesionales de las instituciones de práctica acerca de la celebración de convenios, de los reglamentos de práctica y de las normas mínimas para los estudiantes.

En contraste, los docentes de las práctica manifiestan estar en pleno conocimiento de los documentos legales que orientan la actividad de la práctica académica al igual que los jefes de laboratorio y/o directivos de las instituciones de práctica.

En lo referente a los procesos de inducción del personal que ingresa a la actividad de docencia servicio, se resalto que para los estudiantes del programa de bacteriología y laboratorio clínico se programa una inducción semestral para cada nivel de práctica, que incluye una serie de actividades que les permite comprender bien el proceso que inician. De igual manera, en los escenarios de práctica una vez llegan los estudiantes en la mayoría de las instituciones se les facilita hacer el reconocimiento de la infraestructura física, también se les dan a conocer los documentos orientadores de las políticas institucionales como son la misión, visión, objetivos, reglamento interno y manuales de convivencia, entre otros.

En general, se aprecia que para los profesionales que cumplen con las funciones de docencia servicio, no existe un programa de inducción a la docencia, el ejercicio de la actividad se asigna al azar y se reduce 
a la capacidad de ser docentes por su formación profesional, así como, por las políticas y direccionamiento de la institución de práctica. El sentimiento generalizado es que los profesionales imparten docencia, lo hacen por que les gusta y en muy contados sitios porque esa es su formación.

También se observa que no existen documentos que sustentan en lo pedagógico el desarrollo de la actividad de docencia servicio. Los docentes de práctica también manifiestan que no existe un programa específico para ellos de inducción a todas las actividades académico administrativas que demanda esta labor.

Indicadores: (ii) comité docencia servicio: con respecto a si la relación docencia-servicio es planeada, construida, supervisada y evaluada por un comité de docencia-servicio, los coordinadores manifiestan que unos pocos sitios de práctica cuentan con el establecimiento formal del comité de docencia-servicio y que en las instituciones donde no existe, se han creado los comités de integración de universidades en los cuales se hace participe a la universidad de la decisiones que se toman, con respecto al fortalecimiento de la práctica académica y que la universidad sólo tiene participación como miembro activo en el comité de docencia-servicio del hospital Rafael Uribe.

De igual forma no existe divulgación efectiva de los temas tratados y decisiones tomadas en los comités de los cuales no hace parte la universidad. Los empleadores y profesionales de práctica dicen no estar bien informados sobre la existencia, los objetivos, el funcionamiento y por consiguiente de las decisiones tomadas en estos comités.

Con respecto a la existencia de información verificable del comité de docencia-servicio sustentada en actas, no existe en la mayoría de los casos por desconocimiento acerca de la conformación de dichos comités; vale la pena aclarar que siempre que se hace alusión a información verificable se piensa en las actas de visita, que levantan los coordinadores de práctica en cada una de las supervisiones a los estudiantes, las cuales además son la principal fuente de información para analizar dificultades que se presentan en el transcurso de su desarrollo y son material fundamental de análisis para proponer estrategias de mejoramiento.

En cuanto a que si las decisiones tomadas en estos comités son tenidas en cuenta para el diseño de políticas institucionales, la mayoría de los sectores involucrados en el estudio manifiestan que no tienen conocimiento al respecto, sólo uno de los empleadores entrevistados afirma que el subgerente de los servicios de salud reúne periódicamente a todas las escuelas y universidades que tienen estudiantes en rotación, se levanta el acta, se archiva con un consecutivo, el cual está disponible para cualquier órgano de control, se proponen planes de mejoramiento y los coordinadores de los servicios son los responsables de hacerle el seguimiento a lo estipulado en el convenio.

La población entrevistada en el sector profesional y empleadores en general reitera que la información que se tiene en cuenta para los planes de mejoramiento es obtenida del resultado de las visitas periódicas que realiza la universidad. Los docentes de práctica manifiestan que aunque en la mayoría de los sitios con los cuales se tiene convenio existe los comités de docencia-servicio, no se conocen las decisiones tomadas en ellos cuando la universidad no tiene representación en ellos.

Indicadores: (iii) plan de aprendizaje: respecto a si la actividad de práctica está orientada por un plan de aprendizaje de docencia-servicio, hay discrepancia entre los resultados obtenidos en la encuesta y en las entrevistas. En la encuesta toda la población de estudio, manifiesta que los planes de aprendizaje se han desarrollado en alto grado; mientras que en las entrevistas los profesionales de las entidades de práctica afirman casi en su totalidad, que la actividad de docencia-servicio no se orienta por un plan de aprendizaje sino que cada profesional de acuerdo al trabajo diario diseña las diferentes estrategias y actividades de aprendizaje. 
Los docentes de práctica afirmaron que existen planes de trabajo y que en el momento en todos los sitios de práctica reposa el documento con la firma del jefe del laboratorio y de la decana de la facultad.

En lo concerniente a la suficiencia de los recursos disponibles para el desarrollo de las prácticas, los tres sectores entrevistados y encuestados coinciden en calificar esta suficiencia como buena. Para los empleadores las instituciones les brindan a los estudiantes en rotación recursos suficientes como son: equipos, materiales, reactivos, muestras biológicas, bibliografía y ayudas informáticas suficientes para que realicen todos los procesos concernientes a cada nivel de práctica, pero de igual forma manifiestan que la universidad no aporta ningún recurso de los anteriormente mencionados.

Los profesionales que orientan la docencia-servicio, reiteran lo expuesto por los empleadores y agregan que la institución en lo posible también les aporta los elementos básicos de bioseguridad personal, aunque en algunos momentos la disponibilidad de recursos no lo permiten.

Respecto a que si la capacitación para el aprendizaje práctica corresponde a los objetivos y logros definidos en la actividad de docencia-servicio, la óptica de los tres sectores indagados coincide en afirmar que existe correspondencia entre la capacitación para el aprendizaje práctico y el logro de los objetivos propuestos, pues el tiempo que se dispone para estas rotaciones es suficiente y se fortalece constantemente la capacitación disciplinar de los profesionales, sin embargo, los profesionales que orientan la actividad de docencia-servicio declaran que estos logros van muy ligados a los intereses y motivaciones que tienen los estudiantes, de igual forma ven que el desarrollo de esta actividad y el contacto con los estudiantes les genera valor agregado por cuanto les permite mantenerse en constante actualización.

Acerca de el monitoreo de la actividad de práctica, este indicador fue bien evaluado por los involucrados en esta actividad; vale la pena diferenciar los dos tipos de monitoreo que se realizan: 1 . En las instituciones de práctica donde efectúa un monitoreo constante en cada una de las secciones por las cuales rotan, integrando procesos de evaluación formativa y sumativa allí se reconocen debilidades y fortalezas de los estudiantes para retroalimentar el proceso académico y 2 . El que ejecuta la universidad a través de la supervisión mediante las visitas periódicas que realizan los docentes de práctica cuyo objetivo es verificar el avance de los procesos de aprendizaje y proponer acciones de mejoramiento.

Los docentes de práctica manifestaron, que además de la visitas periódicas que se realizan a las instituciones de rotación se hace un seguimiento serio y riguroso del desarrollo general de la actividad en reuniones del grupo coordinador con participación de la decana de la facultad, con una frecuencia de dos veces al mes y con el objetivo de presentar informes parciales de dicha actividad y de proponer estrategias de mejoramiento que eleven la calidad académica. Algunos profesionales y empleadores manifestaron que las visitas de los coordinadores de práctica han disminuido en frecuencia, sin embargo esto en ningún momento ha afectado el correcto desarrollo de la actividad.

Indicadores: (iv) desarrollo docente: la actividad de docencia-servicio se vio fortalecida por planes de capacitación en diferentes modalidades para el perfeccionamiento del quehacer docente. Los entrevistados y encuestados consideraron que el desarrollo es bueno, aunque no existe hasta el momento, ningún plan específico en este sentido.

En la entrevista, se observó que cuando se mencionaba la capacitación se hacia referencia es a la de tipo disciplinar, la cual responde además a las necesidades de actualización del personal en salud. Así mismo, los profesionales y empleadores mencionan los cursos de actualización y perfeccionamiento profesional que les ofrece la universidad como contraprestación, dentro del convenio para 
la relación docencia-servicio. Sin embargo, se encontró que no existe ningún tipo de actividad que se pueda relacionar con capacitación de tipo pedagógico, tema sobre el cual opinan que es de suma importancia y que sería necesario contemplar un programa de capacitación en esta modalidad con el fin de obtener mayor eficiencia en las actividades propias de la docencia.

Se destaca la necesidad de mejorar los programas de actualización que ayuden al desarrollo de las prácticas académicas, no solo para los docentes de práctica, si no para los profesionales de las instituciones de práctica. Acerca de los criterios y perfiles de selección para la escogencia del personal profesional que orienta las funciones de docencia-servicio, se observó que los entrevistados y encuestados, manifestaron que no existen criterios definidos para seleccionar a los coordinadores de práctica, ni para los profesionales que orientan la actividad de práctica de los estudiantes.

Indicadores: (v) convenios: en cuanto a la claridad en los convenios y las reglas de relación y compromiso que adquieren las dos partes, la opinión de los profesionales fue contundente en afirmar que no existe suficiente socialización de los convenios para todos los actores de la relación docente-asistencial, a veces no quedaban claros los compromisos de las instituciones prestadoras de servicio frente al aprendizaje de los estudiantes.

$\mathrm{Al}$ respecto, los empleadores y las coordinadoras de práctica afirmaron que en la realidad, los empleadores son quienes firman el convenio y el coordinador de práctica de la institución es el encargado de monitorear el proceso, la información sobre el contenido de los convenios es conocida por un selecto grupo de la parte directiva y realmente no es socializado con el resto del personal.

Con relación a la ejecución de actividades de bienestar en los escenarios de práctica, los empleadores y los profesionales reconocen que estas actividades están relacionadas directamente con las condiciones de infraestructura física, así como, con las posibilidades de acceso a la consulta bibliográfica, al uso de Internet, a la dotación de implementos del programa de bioseguridad; en general informaron que se procura la integración de estudiantes a las actividades socio culturales que se desarrollan con el personal del laboratorio, pero manifiestan que existe un vacío en el aporte de recursos por parte de la universidad para el bienestar de los estudiantes en la actividad de práctica.

Para los estudiantes, las instituciones de práctica los tienen en cuenta en la mayoría de actividades científicas, culturales y deportivas, aunque muchas veces no pueden participar por el horario en que se desarrollan; en cuanto a lo que la universidad les ofrece anotan, que no pueden asistir a las jornadas culturales programadas debido a los numerosos compromisos adquiridos en el curso de los periodos académicos.

Con relación a existencia de requisitos que amparan el ejercicio del proceso de servicio por parte de los estudiantes, se aseguro que existe un cumplimiento en la presentación de documentos, tales como: afiliación de los estudiantes al sistema de seguridad social, seguro de accidentes, esquema de vacunación y póliza de responsabilidad civil colectiva (6).

\section{Conclusiones}

El estudio permitió una autoevaluación de la estructuración y funcionamiento del programa de las prácticas académicas, del programa de bacteriología y laboratorio clínico, frente a las condiciones mínimas de calidad propuestas por el Consejo Nacional de Acreditación (3), destacándose los siguientes aspectos: primera categoría de análisis, relación de los procesos académicos: las prácticas académicas ofrecen espacios para el fortalecimiento de las relaciones interpersonales e interdisciplinarias de los estudiantes, como apoyo para el crecimiento personal y profesional; es un puente de acercamiento con la realidad laboral y ocupacional. Así mismo, es considerada por los estudiantes como estrategia trascendental para el fortalecimiento de competencias. 
El Programa de Bacteriología y Laboratorio Clínico de la UCMC ha diseñado un completo y eficiente plan académico para el desarrollo de las prácticas académicas, las cuales se despliegan en tres niveles consecutivos durante los tres últimos semestres de la carrera, y es así como en la actualidad se encuentran 52 convenios de cooperación, que vincula semestralmente un promedio de 323 estudiantes, ubicadas en 63 instituciones de rotación, distribuidas en una amplia zona geográfica de la ciudad de Bogotá y municipios anexos, lo que aporta 152 zonas de práctica en 39 áreas de desarrollo profesional.

La vinculación de los docentes para el desarrollo del programa de la práctica académica, se presenta en dos modalidades: profesores de la universidad, los cuales cumplen con las funciones de coordinación, monitoreo y supervisión de la actividad, y los profesionales vinculados a las instituciones prestadoras de salud y otras instituciones, quienes actúan en forma integrada, tanto en la prestación de servicios como en los programas académicos que se desarrollan en la práctica; los cuales no son seleccionados formalmente de acuerdo con los criterios de calidad o perfiles definidos para realizar esta labor, y en muchas ocasiones no cuentan con la formación docente requerida, impartiendo docencia a expensas de su experiencia profesional, vocación y o perfeccionamiento disciplinar, con estos profesionales no se formaliza vínculo laboral con la universidad.

Las prácticas académicas son orientadas por un plan de aprendizaje, el cual se elabora en consenso entre la universidad y los escenarios de práctica con los que se tiene convenio. En estos planes son ampliamente descritos los contenidos propuestos, los cuales están acordes con los objetivos educacionales y las competencias profesionales y laborales. De igual manera, el plan es conocido por los directivos y coordinadores de práctica, pero no es lo suficientemente socializado con los profesionales de las entidades de salud encargados de los procesos de docencia-servi- cio, conduciendo en muchas ocasiones a realizar una docencia improvisada, dejando de lado las actividades complementarias de formación integral como son: participación en actividades académicas distintas a la docencia, investigación y proyección social (actividades culturales, recreativas, participación en actividades electivas como la presentación de seminarios y club de revistas entre otros).

Respecto a los enfoques del aprendizaje y o metodologías propuestas, se encontró compatibilidad entre las técnicas y procedimientos de laboratorio desarrollados por los estudiantes con las normas vigentes de calidad en la prestación de servicios (8) y los conocimientos adquiridos en la universidad. Estas actividades son monitoreadas permanentemente por los profesionales de las entidades de salud y por los docentes coordinadores de práctica de la universidad, situación que ha permitido una buena retroalimentación de los procesos. De cada sesión de monitoreo, queda constancia en actas de visita.

Se observa que hacen falta espacios para la definición de políticas y estrategias interdisciplinarias en el manejo de problemas actuales en salud, lo que debería generar proyectos de investigación, como fruto del desarrollo de la práctica, esto puede ser atribuido a la falta de tiempo para la inclusión de estas actividades durante la permanencia de los estudiantes en los escenarios de práctica.

Otro aspecto en el cual se observan carencias, es en el sistema de evaluación de las prácticas formativas especialmente en las instituciones de práctica, pues no se cuenta con formación pedagógica en evaluación y no se establecen criterios que correspondan a los parámetros incluidos en los objetivos propuestos desde el programa, dejando de lado los procesos investigativos y de proyección social.

La relación de las prácticas académicas con el entorno no esta bien precisada por ninguna de las partes, no se observan políticas claras ni definidas que se apoyen en documentos verificables, donde se per- 
ciba la búsqueda de mejores posibilidades de impacto en el entorno donde se realizan las prácticas académicas, tampoco se comprueban cambios derivados de acciones generadas en la práctica académica; en cierto modo se confunde el reconocimiento con el entorno con los procesos de asistencia por parte de los estudiantes y algunos profesionales de los servicios.

El desarrollo de estrategias de formación en la práctica académica que fortalecen la investigación, no se ha visto favorecido con la generación de proyectos de investigación que resulten como producto de una práctica formativa, orientada por una relación de docencia-asistencia, para apoyar los planes de mejoramiento de la problemática en salud .

Con respecto a la Segunda Categoría de Análisis, relación docencia-servicio, la universidad ha establecido un conjunto de procesos y procedimientos que propenden por una efectiva ejecución del objeto de esta relación (6), dentro de estos procesos se encuentran: la conformación del comité de docencia-servicio, con cada una de las instituciones prestadoras de salud y el plan de aprendizaje que orienta específicamente las actividades y metodologías a desarrollar en conjunto.

Sin embargo, pese a que existen fortalezas en la estructuración legal para el desarrollo de la actividad de docencia-servicio, se encuentran debilidades en los sistemas de comunicación e información del convenio, en las decisiones tomadas en el comité de docencia servicio, en los planes de aprendizaje y reglamentos en general, ya que son bien conocidos por los directivos de las instituciones y por los coordinadores de la práctica, pero no por los profesionales que adelantan la actividad de docencia-asistencia con los estudiantes; por lo tanto pone en peligro la eficiencia y eficacia en el logro de los objetivos.

El estudio deja ver que existen aspectos que debilitan la relación docencia-servicio, el más importante, la falta de definición de acuerdos institucionales que garanticen los recursos financieros necesarios para ejecutar las actividades derivadas de los programas; de manera que los recursos con los que se cuenta para la realización de la actividad, son aportados únicamente por las entidades de práctica.

\section{Referencias}

1. Ministerio de Salud de Colombia Consultoría y Gestión S.A. La Formación del Personal en Salud en Colombia - Un Reto al Futuro. Bogotá: Tecno Press ediciones Ltda.; 2002.

2. Ministerio de Salud de Colombia. Decreto No. 917. Requisitos básicos de calidad para instituciones y programas de educación en el área de la salud. 2001.

3. Concejo Nacional de Acreditación. Criterios y procedimientos para la acreditación previa de los programas académicos de pregrado y de especialización en educación. Bogotá: 2003.

4. Unión Temporal ASCOFAME, ASSALUD, AUPHA, CES. Modelo de autoevaluación y Autorregulación para Programas de educación superior del área de la salud. ARFO Editores e Impresores; Bogotá: 2002.

5. Ministerio de Salud de Colombia. Ley 100. Seguridad social en salud. 1993.

6. Ministerio de Salud de Colombia. Decreto 190. Convenios docente asistenciales. 1996

7. Hernández Sampieri R. Metodología de la Investigación. México: Editorial Mc Graw Hill; 1998. P.15-40.

8. Ministerio de Salud de Colombia. Decreto No. 2309. Habilitación de instituciones prestadoras de servicios de salud. 2002.

Correspondencia: revistanova@unicolmayor.edu.co 